\title{
La regulación de los efectos laborales de la subcontratación: el Perú en América del Sur
}

\author{
The regulation of the labor effects of subcontracting: \\ Peru in South America
}

\author{
WILFREDO SANGUINETI*
}

Resumen: El presente artículo pretende situar los cambios operados en el tratamiento jurídico de los efectos laborales de la subcontratación de actividades productivas en el Perú dentro del contexto de una tendencia más general a regular este fenómeno, tendencia operada en varios países de América del Sur de manera coincidente, con el fin de detectar sus puntos de coincidencia y sus singularidades. Asimismo, se interroga sobre la aptitud de las soluciones normativas introducidas para hacer frente a los problemas generados por el nuevo modelo productivo que expresan estas prácticas y ensaya propuestas para superar en el futuro sus debilidades.

Palabras clave: subcontratación - tercerización - descentralización productiva - outsourcing - derechos laborales

Summary: This article aims to place the operated changes in legal treatment of labor effects of the outsourcing of productive activities in Peru within the context of a more general trend to regulate this phenomenon operated in several countries in South America in a coincident way, in order to identify their points of coincidences and their singularities. It also questions the aptitude of regulatory solutions introduced to face up to problems generated by the new productive model which express these practices and it tests proposals to overcome in the future their weaknesses.

Keywords: subcontracting - decentralization of production - outsourcing labor rights

CONTENIDO: I. UN TESTIMONIO SOBRE LOS ORÍGENES DE LA NUEVA REGULACIÓN DE LOS EFECTOS LABORALES DE LA SUBCONTRATACIÓN DE ACTIVIDADES PRODUCTIVAS EN EL PERÚ.- II. UNA LLAMATIVA COINCIDENCIA: EL INTERÉS POR REGULAR EL MISMO FENÓMENO EN DIVERSOS PAÍSES DE AMÉRICA DEL SUR.- III. DOS ENFOQUES DISTINTOS SOBRE LA MANERA DE ENCARAR LA SUBCONTRATACIÓN DESDE EL DERECHO DEL TRABAJO.- IV. EL ENFOQUE PATOLÓGICO: LA SUBCONTRATACIÓN COMO ACTIVIDAD PROHIBIDA.- V. EL ENFOQUE FISIOLÓGICO: LA SUBCONTRATACIÓN COMO ACTIVIDAD REGULADA.- VI. UNA CUESTIÓN, A PESAR DE TODO, PENDIENTE: LA REGULACIÓN DE LAS POSIBLES CONSECUENCIAS LABORALES NEGATIVAS DEL RECURSO LÍCITO A LA SUBCONTRATACIÓN.- VII. ALGUNAS ALTERNATIVAS VIABLES PARA EMPEZAR A AFRONTAR EL PROBLEMA DESDE LA AUTONOMÍA COLECTIVA.

* Catedrático de Derecho del Trabajo de la Universidad de Salamanca. Licenciado en Derecho por la Pontificia Universidad Católica del Perú y doctor en Derecho por la Universidad de Salamanca. 


\section{UN TESTIMONIO SOBRE LOS ORÍGENES DE LA NUEVA REGULACIÓN DE LOS EFECTOS LABORALES DE LA SUBCONTRATACIÓN DE ACTIVIDADES PRODUCTIVAS EN EL PERÚ}

Una ocasión como esta, en la que luego de décadas de vinculación con la Facultad de Derecho de la Pontificia Universidad Católica del Perú, mi universidad de origen, tengo por primera vez la oportunidad de escribir en su revista, constituye un momento propicio para combinar la reflexión académica con el testimonio y la confidencia personales. Una licencia que de ordinario no nos permitimos quienes nos dedicamos a la docencia universitaria. Voy a empezar por ello este estudio, integrado en el número monográfico de Derecho dedicado a hacer balance de las reformas y transformaciones experimentadas por el Derecho del Trabajo en el Perú a partir de la primera oleada reformadora iniciada en los años noventa, compartiendo con sus lectores una experiencia personal que, con toda seguridad, ilustra más que cualquier referencia extraída de los repertorios legislativos y jurisprudenciales la naturaleza y los alcances del trascendental fenómeno que me propongo presentar.

Entre marzo y julio de 2004 tuve ocasión de desempeñarme como Jefe del Gabinete de Asesores del Ministro de Trabajo de nuestro país, atendiendo a la invitación que me formuló mi maestro de mis primeros años de universidad, el profesor Javier Neves Mujica. Los desafíos que enfrentaba el nuevo equipo de dirección del Ministerio eran inmensos. El Derecho del Trabajo había sido objeto en el Perú, a lo largo de los noventa, como todos sabemos, de un proceso de aguda flexibilización de signo autoritario, liberalizador en lo individual e intervencionista en lo colectivo, cuyos efectos sociales desestabilizadores era preciso tratar de equilibrar de algún modo. Esta era, sin embargo, una tarea que había venido siendo postergada por los Gobiernos que se sucedieron desde el retorno a la democracia en 2001. Nuestros primeros esfuerzos estuvieron dirigidos, por ello, a valorar la posibilidad de introducir al menos los cambios imprescindibles en la legislación vigente, particularmente en materia de relaciones colectivas de trabajo, mientras avanzaba la tramitación de un proyecto de Ley General de Trabajo que afrontaría integralmente la situación. Pronto tomaríamos conciencia, no obstante, de que tan importante como lo anterior era ofrecer alguna respuesta a un fenómeno cuyos efectos empezaban a hacerse patentes por entonces en el país. Me estoy refiriendo al recurso sistemático a la subcontratación de actividades productivas, en particular en los sectores extractivos y de servicios. Una práctica sobre cuyas negativas consecuencias, tanto sobre la calidad del empleo y las condiciones laborales de los trabajadores afectados, como respecto de la efectividad de los derechos colectivos, empezaban a acumularse las evidencias. 
El panorama que entonces comenzaba a apuntarse ante nosotros era, matices aparte, en el fondo coincidente con las advertencias procedentes de la literatura especializada. Dentro de esta, constituye un lugar común afirmar que la subcontratación de actividades productivas es una herramienta de reconocida utilidad para mejorar la eficiencia y la capacidad adaptativa de las empresas, al permitirles concentrarse en el desarrollo de sus competencias nucleares, confiando la ejecución de las demás a colaboradores externos especializados. Sin embargo, bien que con menos intensidad, los estudiosos del fenómeno coinciden en destacar cómo, a la cada vez mayor difusión de estas prácticas, no es ajena la posibilidad que abren de obtener importantes reducciones en los costos asociados al factor trabajo.

El mecanismo que permite conseguir ese resultado es bastante simple. Se basa en la evitación, mediante el recurso a empresas auxiliares dotadas de personalidad diferenciada, de la configuración de una relación jurídica directa entre las sociedades que recurren a este mecanismo y los trabajadores que se encargan de atender sus necesidades. Este hecho, en apariencia puramente formal, hace posible una importante reducción de la calidad del empleo y las condiciones de trabajo de dicho personal. Esto es así en la medida en que, al evitarse la configuración de dicha relación, tanto la duración de los contratos de trabajo como las retribuciones y demás beneficios de quienes desarrollan las labores exteriorizadas dejan de depender de la empresa titular del encargo para hacerlo del contratista.

Lo anterior supone, antes que nada, que la vigencia de las relaciones de trabajo de dicho personal no está sujeta ya a las vicisitudes del desarrollo de la actividad productiva de la empresa principal, para vincularse a las de la contrata. El fin de esta se constituye, así, en un motivo susceptible de ser alegado para la extinción de los contratos de trabajo, así la actividad siga siendo necesaria para la principal; en tanto que la dificultad de garantizar el empleo más allá de la duración del encargo se convierte en una causa susceptible de ser utilizada para fundamentar la celebración de contratos de duración determinada, incluso cuando satisfagan necesidades permanentes. De allí que se suela identificar la sustitución de empleo fijo por temporal como uno de los principales efectos de la externalización de actividades productivas.

A este efecto se añaden las consecuencias reductoras que este mecanismo puede desplegar sobre los salarios de los trabajadores de contrata. Debe tenerse presente que, al no poseer vínculo con el titular del encargo, las condiciones de trabajo de esos trabajadores no tienen ya por qué ser similares a las que esta aplica a su personal. Antes bien, estas dependen solo del contratista. Un contratista que debe ofrecer el servicio en condiciones que hagan más provechoso recurrir a él que 
contratar personal directamente. El resultado de esta tensión es por lo general una devaluación de las condiciones del personal de contrata. Una operación que viene facilitada por la no aplicación al mismo del convenio colectivo al que están sujetos los trabajadores de la principal, bien por ser uno de empresa, o bien por situarse el contratista, debido a su especialización, fuera de su ámbito funcional, cuando se trata de un convenio sectorial.

Naturalmente, frente a ello existiría la posibilidad de recurrir a la acción sindical y a la negociación colectiva con el fin de reducir la brecha generada. Las propias características de los procesos de externalización contribuyen, no obstante, a reducir también la efectividad de estos derechos, al acentuar dificultades de sindicación de estos trabajadores, en especial debido a la precariedad de su condición, a la vez que obstaculiza la articulación de la defensa de sus intereses con los demás colectivos afectados, disgregados en una multitud de empresas de pequeña dimensión, convirtiendo en inviable o ineficaz la negociación a nivel colectivo de sus condiciones laborales.

Como he dicho, las evidencias de que todo lo anterior se venía produciendo en nuestro país hacia el año 2004 eran abundantes. Estas no se reflejaban tanto en las estadísticas laborales, por lo general poco atentas a la medición de estos efectos, como en los conflictos laborales y sociales que, a partir de la extensión de estas prácticas, se venían produciendo. Unos conflictos a los cuales subyacía de forma constante la misma denuncia de la situación de precariedad laboral de los trabajadores de contrata, las diferencias existentes entre los beneficios laborales de estos respecto de los pertenecientes a las empresas titulares de la actividad productiva principal, en algunos casos francamente escandalosa, y la constatación de la ineficacia de los mecanismos de representación sindical y contratación colectiva para hacerles frente.

En tales condiciones, nos pareció de la máxima importancia, a quienes por entonces asumíamos la labor de diseño de las políticas de intervención de la Administración del Trabajo, la adopción de medidas que, sin impedir las externalizaciones basadas en razones empresariales atendibles, impusiesen al menos algún tipo de cautela a aquellas que puedan perseguir exclusivamente una degradación de las condiciones de trabajo.

Empezó así un laborioso proceso de preparación de un proyecto de norma reglamentaria, diseñada a partir de los espacios abiertos por la legislación vigente en materia de intermediación laboral, con el fin de ofrecer al menos una primera respuesta al fenómeno que sentase las bases para intervenciones más incisivas en el futuro. Las líneas maestras de ese proyecto fueron perfilándose de manera laboriosa a lo largo del 
tiempo consumido en su discusión, hasta asentarse sobre tres criterios básicos: a) la necesidad de definir de manera precisa los elementos que distinguen los supuestos lícitos de subcontratación de actividades productivas de los de mera cesión de personal, con los que algunos de los supuestos de subcontratación más frecuentemente utilizados parecían mantener una llamativa proximidad; b) la conveniencia de imponer a la empresa principal un deber de vigilancia sobre el cumplimiento de las normas laborales, preventivas y de Seguridad Social por los contratistas y subcontratistas, derechos de carácter colectivo incluidos, con posibilidad de que los trabajadores de contrata puedan dirigirse a ella con el fin de denunciar los incumplimientos que puedan afectarlos; y c) la consideración de dicha empresa como responsable solidaria por las obligaciones laborales y de Seguridad Social contraídas por los mismos, cuando sus labores se desarrollen en el centro de trabajo de la primera y siempre que no hubiese cumplido con efectuar la antes citada labor de vigilancia.

La iniciativa fue avanzando no sin dificultades a lo largo de sucesivas etapas en las que se recabó la opinión de las más diversas instancias, hasta llegar a dos memorables reuniones en julio de 2004, en las cuales conseguimos el compromiso de los responsables de las asociaciones representativas, tanto de las empresas prestadoras de servicios públicos como de las empresas mineras. Un gremio, este último, considerado el más poderoso del país y, además, especialmente concernido por el proyecto. El proyecto terminaría por estancarse, por paradójico que pueda parecer, al interior del propio Gobierno, al ser observado por el Ministerio de Economía. Por cierto, no por objeciones singulares a su contenido, sino debido a su oposición de principio a cualquier norma que pretenda regular el desenvolvimiento de la actividad económica.

Pero si la acción de las autoridades económicas terminó por frenar el proyecto, no consiguió poner entre paréntesis los conflictos que el recurso masivo a la subcontratación venía generando, en especial en las zonas más deprimidas del país, en medio de las cuales se asentaban prósperos proyectos de explotación minera. El resultado de estas tensiones fue la aprobación, ya en el marco de las negociaciones dirigidas a la celebración de un tratado de libre comercio con los Estados Unidos de América, dentro del cual se hizo presente la presión de las organizaciones sindicales norteamericanas en respaldo de las peruanas, de la ley 29245, de 2 de junio de 2008, a través de la cual se reguló por vez primera la prestación de los denominados «servicios de tercerización», recuperando algunas de las ideas esbozadas por el proyecto mencionado e incluyendo otras nuevas. 


\section{UNA LLAMATIVA COINCIDENCIA: EL INTERÉS POR REGULAR EL MISMO FENÓMENO EN DIVERSOS PAÍSES DE AMÉRICA DEL SUR}

El caso peruano, en el que la dinámica social terminó por imponer una respuesta legislativa al fenómeno, no era un caso aislado. En realidad, procesos similares venían gestándose paralelamente en varios países de la región, donde el recurso masivo a las prácticas descritas y sus peyorativas consecuencias venían siendo fuente de creciente descontento e importantes tensiones. Ello terminaría por dar lugar, con una muy llamativa proximidad en el tiempo y un claro paralelismo en los objetivos, a la aprobación de normas reguladoras de sus efectos laborales en varios países de la región.

La secuencia de intervenciones normativas se inicia en Chile, donde en 2006 fue aprobada la ley 20.123, reguladora del «trabajo en régimen de subcontratación», continúa en 2007 en Uruguay, con la aprobación de la ley 18.099, que establece normas para la «protección» de los trabajadores «ante los procesos de descentralización empresarial», reformada al año siguiente por la ley 18.251; y se consolida en 2008 mediante la aprobación en nuestro país de la aludida ley 29.245, cuyos alcances serían luego precisados por el decreto legislativo 1.038, y la adopción en Ecuador del mandato constituyente número 8 y la aprobación de la Constitución de ese país, instrumentos a través de los cuales se opta por prohibir «la intermediación laboral y la tercerización». Estos países se suman a Venezuela y Argentina, que en 1997 y 1998 respectivamente habían optado por regular los aspectos laborales de estas prácticas mediante sendas reformas de sus leyes Orgánica del Trabajo y de Contrato de Trabajo, aunque en el primero de los países se produciría alguna intervención normativa posterior. Y también a Colombia, que nada menos que en 1965 se inclinó ya por introducir una regulación de signo tutelar de la subcontratación a través del decreto 2.351, modificatorio del artículo 34 del Código Sustantivo del Trabajo.

La aprobación de estas normas, de evidente vocación tutelar, es expresión de una tendencia de más amplio alcance que se ha venido registrando en los últimos años en la región, cuyo rasgo más destacado viene dado por la recuperación de la preocupación por el cumplimiento de los fines equilibradores que tradicionalmente han sido asignados a las normas laborales, luego de una década de cuestionamiento de los mismos y de retrocesos a nivel legislativo.

Esta tendencia se ha manifestado desde finales de los años noventa de muy distintas maneras. Por ejemplo, a través de reformas constitucionales que han incrementado el catálogo de derechos laborales fundamentales o han concedido aplicabilidad directa a los sancionados por normas internacionales, en los casos de Brasil, Argentina, Colombia o Venezuela; 
mediante la labor de los tribunales superiores o constitucionales, que se han servido de las normas del máximo nivel para poner en entredicho algunos de los aspectos más cuestionables de la legislación de la década precedente, especialmente tratándose de Argentina, Colombia y el Perú; por medio de la adopción de reformas de signo re-regulador antes que desrregulador, como ha ocurrido al menos en Chile, Venezuela, Argentina y Uruguay; o, en fin, a través del impulso de reformas procesales dirigidas a garantizar una tutela judicial más eficaz de los derechos laborales, como ha ocurrido también en Venezuela, Chile, Colombia o, nuevamente, nuestro país.

El tratamiento tutelar de los derechos de los trabajadores en los supuestos de subcontratación de actividades productivas introducido por varios países de la región a través de las normas que han sido citadas constituye, una manifestación más, sin duda estelar, de este cambio de orientación. No debe perderse de vista que, como habrá ocasión de destacar más adelante situando nuestra norma sobre la materia, en el contexto del conjunto de las aprobadas en la región, los cambios introducidos no son aquí de mero ajuste o adaptación, sino que afectan sustancialmente al tratamiento de una institución que hasta entonces no había sido objeto en la mayor parte de los casos — desde luego, en el nuestro- de la atención del legislador, cuya importancia resulta, por lo demás, a la luz de los problemas a los que había venido dando origen y la demanda de regulación que se generó a partir de ellos, muy superior a la que en principio pudiera atribuírsele.

Lo anterior supone que los legisladores de los países concernidos han optado, en los últimos años, no solo por replantearse algunos de los contenidos más relevantes de las normas laborales aprobadas durante la década precedente, sino también por imponer garantías frente al uso cada vez más extendido de un mecanismo que permite, como se ha indicado, obtener importantes reducciones en los costos laborales sin «tocar» la legislación vigente, sobre la base de debilitar la efectividad de los derechos individuales y colectivos de los trabajadores mediante la interposición del «diafragma» de la personalidad jurídica entre la empresa principal y los trabajadores que atienden las actividades integradas en sus procesos productivos.

El resultado ha sido la puesta en marcha, de manera coincidente en un importante grupo de países del área sudamericana, de un nuevo tipo de reforma laboral, que se añade a las introducidas en la regulación sustantiva de las instituciones clásicas del Derecho del Trabajo y en sus mecanismos de tutela procesal. Este hecho, sin duda llamativo aunque no del todo excepcional dentro de la experiencia comparada reciente, justifica que dediquemos los apartados siguientes a la presentación de sus rasgos más relevantes y al análisis de su potencial efectividad. Todo ello 
con el deliberado propósito de situar los cambios que se han producido en nuestro país en el contexto de los que han operado en la región de la que formamos parte.

\section{DOS ENFOQUES DISTINTOS SOBRE LA MANERA DEENCARAR LA SUBCONTRATACIÓN DESDE EL DERECHO DEL TRABAJO}

Aunque la conciencia en torno a los potenciales efectos negativos de las prácticas externalizadoras parece encontrarse muy extendida en la región, las respuestas adoptadas por los legisladores de los países a los que se ha hecho referencia no son coincidentes.

Una primera y más radical aproximación es la ofrecida por Ecuador, que a través de decisiones al máximo nivel ha optado por prohibir estas prácticas tratándose de las «actividades propias y habituales» de las empresas. La subcontratación o «tercerización», como la denominan dichas normas siguiendo una corriente muy extendida en el subcontinente, queda así relegada a supuestos excepcionales en los que no se configuren los presupuestos de inherencia y habitualidad antes aludidos.

Frente a este enfoque prohibitivo, el resto de países que se han inclinado por regular estas prácticas, incluido el nuestro, parte de admitir su licitud con la sola excepción de los supuestos en que encubran una simple cesión de personal. La intervención del legislador se dirige, por ello, a la previsión de un conjunto de garantías que permitan eliminar o aminorar algunos de los riesgos que las mismas suponen para los trabajadores.

Como se verá, ese sistema de garantías gira en torno al establecimiento de un régimen de solidaridad entre la empresa principal y sus contratistas por las obligaciones laborales y previsionales contraídas durante el encargo que está prevista en todos los casos. Existe, sin embargo, un importante matiz entre un primer grupo, compuesto por Colombia, Venezuela y el Perú, en los que la solidaridad es sancionada de manera directa, y otro, en el que se integran Argentina, Chile y Uruguay, donde la misma está condicionada al incumplimiento por la empresa principal de un conjunto de deberes de vigilancia o control del acatamiento de sus obligaciones por parte de los contratistas, previéndose además la posibilidad de que la primera retenga de las obligaciones pendientes de pago que mantiene frente a estos últimos las cantidades que se adeuden a los trabajadores o las instituciones previsionales con el fin de abonarlas directamente a ambos, pudiendo también proceder a efectuar dichos pagos por subrogación. 
Es evidente que estas dos grandes líneas de intervención son consecuencia de dos puntos de vista distintos sobre la funcionalidad de la figura. Así, no parece difícil deducir que a la decisión del constituyente ecuatoriano de ilegalizar su empleo subyace una contemplación de la «tercerización» como un mecanismo dirigido principalmente a afectar de manera ilegítima los derechos laborales. En cambio, los demás ordenamientos que optan por regular estas prácticas antes que por prohibirlas parecen instalarse en una visión más benigna, de acuerdo con la cual los riesgos que supone para los trabajadores su utilización no le son inherentes sino que se derivan de un uso torticero de las mismas frente al cual es preciso articular garantías.

Es más, el tipo de garantías previsto permite poner de manifiesto cuáles son, a juicio del legislador, tales riesgos. En esta dirección, el hecho de que todos los sistemas se articulen en torno a la responsabilidad solidaria de la principal por las obligaciones de sus contratistas conlleva la admisión implícita de que el problema más relevante o, en todo caso, acucioso que plantea la externalizacion de actividades productivas es uno de garantía de cumplimiento de dichas obligaciones por tales sujetos. Esta orientación se proyecta con especial transparencia tratándose de los tres ordenamientos que condicionan la emergencia de la solidaridad, de manera novedosa, a la no comprobación de ese cumplimiento por parte de los contratistas, convirtiéndola en subsidiaria en caso contrario.

\section{EL ENFOQUE PATOLÓGICO: LA SUBCONTRATACIÓN COMO ACTIVIDAD PROHIBIDA}

La subcontratación de actividades productivas se encuentra prohibida, como se ha anticipado, únicamente en el caso de Ecuador. Esta decisión fue adoptada inicialmente por el mandato constituyente número 8 , cuyo contenido sería ratificado más tarde con algún matiz por el artículo 327 de la Constitución de este país. La razón de esta drástica decisión aparece expresada con toda claridad y transparencia en la parte considerativa de la primera de dichas normas, en la que se indica que la «tercerización» constituye una forma «extraña» y «precaria» de trabajo que «es imperativo suprimir y prohibir» en la medida en que a través de ella se «vulneran los derechos del trabajador y los principios de estabilidad, de pago de remuneraciones justas, de organización sindical y contratación colectiva». La minoración de los salarios y condiciones de trabajo, así como la reducción de la virtualidad de los derechos colectivos, no son contemplados, de este modo, como potenciales consecuencias del recurso a este mecanismo, como ocurre con frecuencia, sino como efectos ineludiblemente unidos a él. Y desprovistos, además, de cualquier fundamento. La subcontratación se convierte, así, en un 
puro instrumento para afectar injustificadamente los derechos de los trabajadores que ha de ser suprimido en aras de su efectivo respeto.

Con todo, como se ha anticipado, la prohibición no alcanza a todo tipo de externalizaciones sino solo a las que afecten a «las actividades propias y habituales de la empresa», de acuerdo con el artículo 327 de la Constitución ecuatoriana. Quedan de tal modo excluidas todas aquellas que tengan por objeto tareas que no reúnan los dos atributos referidos. En particular, de acuerdo con el mandato constituyente número 8, la prestación de las «actividades complementarias» de «vigilancia, seguridad, alimentación, mensajería y limpieza» (artículo 4), el empleo de «servicios técnicos especializados ajenos a las actividades propias y habituales de la usuaria, tales como los de contabilidad, publicidad, consultoría, auditoría, jurídicos y de sistemas, entre otros» (segunda disposición general), y la contratación de «empresas de servicios técnicos especializados» por «empresas del sector estratégico público» (primera disposición general). Ahora bien, solo para las «tercerizaciones» lícitas que afecten a «actividades complementarias», el artículo 4 de la referida norma introduce la garantía de la «responsabilidad solidaria de la persona en cuyo provecho se presta el servicio», añadiendo que los trabajadores que desarrollen estas actividades «participarán proporcionalmente del porcentaje legal de las utilidades líquidas de las empresas usuarias».

No puede dudarse que, con un sistema como este, se suprime $a b$ radice la posibilidad de que este mecanismo pueda ser utilizado en clave degradatoria de los derechos individuales y colectivos. Este resultado es conseguido, sin embargo, a costa de introducir una muy importante limitación en la libertad de organización empresarial. Y además renunciando al potencial efecto benéfico que las operaciones de este tipo están en condiciones de reportar cuando responden a razones organizativas, técnicas o productivas y no a propósitos como los denunciados por el legislador constituyente. Que esto es así parecen reconocerlo los propios autores de la norma cuando, pensando seguramente en el sector de hidrocarburos, autorizan a las empresas públicas de carácter estratégico a contratar «los servicios técnicos especializados que requieran», sin añadir aquí que estos han de ser «ajenos» a sus «actividades propias y habituales».

\section{ELENFOQUE FISIOLÓGICO: LA SUBCONTRATACIÓN COMO ACTIVIDAD REGULADA}

Las normas de los seis países que parten de admitir la licitud del encargo a terceros de actividades integradas en procesos productivos de mayor dimensión parten de definir los negocios incluidos en su ámbito de aplicación, tanto con el fin de distinguirlos de aquellos que implican 
una pura provisión de personal, que son penalizados en todos los casos con la inclusión de los trabajadores afectados dentro de la plantilla de la empresa cesionaria, como de fijar cuáles son aquellos, de todos los del género, a los que se aplican las garantías por ellas previstas.

Respecto de lo primero, lo habitual es que la noción de «tercerización» aparezca vinculada a la realización por un tercero, en virtud de un acuerdo contractual, de una obra, un servicio o una actividad especializada, la cual deberá ser ejecutada por este con autonomía, asumiendo todos los riesgos y con disposición de una organización y recursos propios, así como de personal a él subordinado. Emblemática resulta aquí la definición aportada en caso de nuestro país por el artículo 2 de la ley 29245, según la cual «se entiende por tercerización la contratación de empresas para que desarrollen actividades especializadas u obras, siempre que aquellas asuman los servicios prestados por su cuenta y riesgo; cuenten con sus propios recursos financiaros, técnicos o materiales; sean responsables por los resultados de sus actividades y sus trabajadores se encuentren bajo su exclusiva subordinación».

Menos coincidencia existe en cuanto a la determinación de los supuestos de subcontratación comprendidos en el ámbito de las normas en cuestión. Un primer sistema relaciona su aplicación a la realización de tareas que formen parte de la actividad normal de la principal, sin importar si son principales, accesorias o conexas y si se desarrollan dentro o fuera de sus instalaciones. Este sistema, caracterizado por la amplitud de su espacio de cobertura, es el imperante en el caso de Uruguay (artículo 1 de la ley 18251). Una segunda opción se basa en la aplicación selectiva del sistema de garantías a cierto tipo de actividades, caracterizadas por su especial vinculación con la actividad de la empresa que realiza el encargo. Así ocurre en el caso de Venezuela, donde la regulación vigente afecta solamente a aquellos contratistas que realicen actividades que puedan ser consideradas, bien «inherentes» al proceso productivo de quien las encarga (constituyen «de manera permanente una fase indispensable» del mismo), o bien «conexas» al mismo (están «íntimamente vinculadas» o «su ejecución o prestación se produzca como una consecuencia» de él). Finalmente, una tercera opción, de aun menor amplitud en cuanto a su ámbito de cobertura, es aquella por la que se inclinan Chile (artículo 183-A del Código del Trabajo) y nuestro país (artículos 4 y 9 de la ley 29245), que concuerdan en recurrir a un criterio de coincidencia espacial, declarando afectadas por estas normas solo a aquellas actividades que se desarrollen continuadamente en los centros de trabajo de la empresa principal.

Naturalmente, se tratadeopciones de políticalegislativa de consecuencias muy diversas, detrás de las cuales se sitúan seguramente valoraciones no coincidentes en cuanto a qué tipo de externalizaciones son aquellas 
que, bien por su mayor peligrosidad o bien por estar en condiciones de justificar más claramente la atribución de responsabilidad al empresario que realiza el encargo, deben ser incluidas dentro del ámbito del sistema de protección diseñado por las normas correspondientes.

En cualquier caso, a pesar de estas notables diferencias de partida, en los tres casos, como se ha anticipado, los sistemas de garantías pivotan en torno a la regulación de la responsabilidad de la principal por las obligaciones laborales y de Seguridad Social de los contratistas. Solo dos países prevén deberes adicionales, vinculados con el suministro de información. Así, en Uruguay, el artículo 4 de la ley 18099 sanciona el derecho de los trabajadores de las contratistas a ser informados por escrito de sus condiciones laborales y salarios, así como de la identidad de la principal. Más completas son las previsiones de la legislación peruana, al haber introducido en la ley 29245, a través de su artículos 4 y 6 , una triple exigencia: a) de especificación de «la actividad empresarial a ejecutar» y las «unidades productivas o ámbitos de la empresa principal» en las que tendrán lugar dentro de los contratos de trabajo, necesariamente escritos, del personal de las contratistas; b) de información por parte de la «empresa tercerizadora», igualmente por escrito, «a los trabajadores encargados de la ejecución de la obra o servicio, a sus representantes, así como a las organizaciones sindicales y a los trabajadores de la empresa principal», sobre «la identidad» de esta última, sobre «las actividades que son objeto del contrato» que tendrán lugar «en el centro de trabajo o de operaciones de la misma», y sobre el «lugar donde se ejecutarán» aquellas; y c) la creación de un Registro Nacional de Empresas Tercerizadoras, que acompañe a los deberes mencionados, en el que deben inscribirse todas las que pretendan desarrollar estas actividades según el artículo 8 de la citada ley. El parentesco con la fórmula del Estatuto de los Trabajadores español, luego de su reforma de 2006, es evidente y constituye una contribución importante a la trasparencia de este tipo de operaciones y al control colectivo de su desenvolvimiento.

La solidaridad de la principal por las obligaciones de los contratistas está prevista, según se ha anticipado, por las legislaciones de los seis países que regulan la materia. E incluso, tratándose del Ecuador, en relación con las «tercerizaciones» admitidas en vía de excepción. Esta responsabilidad afecta, de manera coincidente, a las obligaciones laborales y previsionales contraídas por tales sujetos durante el encargo. Solo en el caso del Perú, lastimosamente el decreto legislativo 1038 optó por limitar a través de su artículo 3 esa responsabilidad a las obligaciones «establecidas por norma legal», con exclusión de «las de origen convencional o unilateral». Una decisión poco coherente con el respaldo que han de tener las manifestaciones del derecho a la negociación colectiva dentro de un Estado Social y Democrático de Derecho como el proclamado por la 
Constitución de nuestro país. Y, además, poco sensible a la utilidad que pueden tener los productos de la autonomía colectiva para reequilibrar los efectos degradatorios de los salarios y las condiciones de trabajo que el recurso a estas técnicas está en condiciones de facilitar, como en su momento se dejó dicho.

En contra de lo que su naturaleza pudiera inducir a pensar, los efectos beneficiosos de la imposición de la solidaridad entre principal y contratista no se agotan en la garantía de pago de los créditos laborales y previsionales en los casos de insolvencia de este último. En realidad, este mecanismo despliega su verdadera utilidad en un momento previo, como es el del cumplimiento adecuado y oportuno de las obligaciones contraídas por el contratista, ya que su imposición constituye un claro incentivo para que las sociedades que recurren a estas prácticas no solo entren en contacto con entidades solventes, sino que ejerzan un control constante de ese acatamiento a lo largo de la vigencia del encargo.

Este es, por lo demás, un efecto que aparece potenciado en los tres ordenamientos que exoneran de responsabilidad solidaria a la empresa principal, convirtiéndola en responsable subsidiaria, si ejerce una labor de control de ese cumplimento sobre sus contratistas.

El origen de este singular mecanismo lo encontramos en la reforma de 1998 de la Ley de Contrato de Trabajo argentina, que estableció a través de sus artículos 17 y 18 la «responsabilidad del principal de ejercer el control sobre el cumplimiento de las obligaciones que tienen los cesionarios o subcontratistas» respecto de sus trabajadores, precisando los documentos a través de los cuales debería llevarse a cabo ese control y señalando que «el incumplimiento de alguno de los requisitos» exigidos por la norma «hará responsable solidario» al primero. Posteriormente, se trasladó a las legislaciones chilena y uruguaya a través de las leyes 20.123 y 18.251 , respectivamente, legislaciones que optaron por configurarlo, matices aparte, como un derecho de la empresa principal «a ser informada» por sus contratistas y subcontratistas «sobre el monto y estado de cumplimiento de las obligaciones laborales y previsionales que a estos correspondan respecto a sus trabajadores» mediante la presentación de los certificados o documentos previstos por las normas correspondientes, con la indicación de que, cuando el obligado «no acredite oportunamente el cumplimiento» de tales obligaciones el «empresario principal podrá retener» de las que tenga a favor del mismo «el monto correspondiente», estando «obligado a pagar con ella» a los trabajadores o la entidad acreedora. Las normas añaden que ese pago podrá hacerse también «por subrogación» y que, cuando el empresario principal «hiciere efectivo el derecho a ser informado» - y, en Chile, el «derecho de retención»-, «responderá subsidiariamente» a las obligaciones referidas. 
Es importante observar, de otro lado, que el cumplimiento del deber de información que, como consecuencia de las previsiones citadas, asumen los contratistas respecto de la principal, no es uno de carácter meramente documental, que pueda entenderse satisfecho con la presentación de determinados documentos al margen del contenido que puedan tener. Por el contrario, del tenor de las normas introducidas por las legislaciones argentina, chilena y uruguaya se desprende que su atención requiere de la acreditación del cumplimiento adecuado e íntegro de todas las obligaciones a las que se encuentra referido; es decir, de la demostración del pago en tiempo y forma. Esto supone que la conversión de la responsabilidad solidaria en subsidiaria solo puede tener lugar cuando se ha obtenido constancia del cumplimiento. $\mathrm{O}$ cuando, no siendo así, se ha procedido a retener las cantidades adeudadas con el fin de pagarlas a los acreedores o se ha realizado el pago por subrogación. Casos en los que, en realidad, el deudor está liberado de toda responsabilidad al no haber deuda alguna pendiente. Por el contrario, la solidaridad opera siempre que existan créditos por satisfacer, por no estar acreditado su pago oportuno e íntegro ni haberse efectuado este por la principal, previa retención o por la vía subrogatoria.

La conversión de la responsabilidad solidaria en subsidiaria funciona, de tal modo, esencialmente como un instrumento dirigido a comprometer al principal en el control de los contratistas. Del mismo modo que el derecho de retención constituye un mecanismo encaminado a hacer posible el pago de las obligaciones pendientes por el principal con cargo a los recursos del propio obligado reticente sin necesidad de recurrir a la mediación judicial o hacer efectiva ningún tipo de responsabilidad.

La anterior es, qué duda cabe, una contribución de capital importancia para la efectividad de los derechos de los trabajadores afectados por estos procesos. De allí precisamente que en su momento optásemos, al elaborar el primer borrador de norma que intentó regular la materia en el Perú, por postular el establecimiento de un sistema de este tipo, menos radical en apariencia respecto del que sanciona de manera directa e ineludible la responsabilidad solidaria de la empresa principal, pero potencialmente más efectivo.

\section{UNA CUESTIÓN A PESAR DE TODO PENDIENTE: LA REGULACIÓN DE LAS POSIBLES CONSECUENCIAS LABORALES NEGATIVAS DEL RECURSO LÍCITO A LA SUBCONTRATACIÓN}

Como se ha podido comprobar, solo el sistema ecuatoriano intenta afrontar, bien que por la vía de la prohibición, las consecuencias adversas que es capaz de tener la descentralización de actividades empresariales sobre la calidad del empleo, los salarios y el ejercicio de los derechos 
colectivos. Los demás sistemas, que sitúan su intervención en el plano del reparto de responsabilidades, se caracterizan, en cambio, por no contener previsión alguna dirigida a regular los efectos no deseables que el recurso lícito a este tipo de operaciones puede ocasionar.

Si acaso, únicamente la legislación de nuestro país contiene algunas previsiones a las que subyace esta preocupación. Es el caso del artículo 7, apartados 3 y 4, de la ley 29245, a través del cual se dispone que la «tercerización de servicios [...] no puede ser utilizada con la intención o efecto de limitar o perjudicar la libertad sindical, el derecho de negociación colectiva, interferir en la actividad de las organizaciones sindicales, sustituir trabajadores en huelga o afectar la situación laboral de los dirigentes amparados por el fuero sindical», añadiendo que, de ser así, los afectados podrán «impugnar las prácticas antisindicales» realizadas.

La introducción de este mandato no es, ciertamente, ociosa. Antes bien, sirve para alertar sobre el potencial uso torticero de este mecanismo con el fin de vulnerar los derechos colectivos, poniendo de manifiesto además la posibilidad de utilizar contra él los medios de reacción previstos por el ordenamiento jurídico. No obstante, es obvio que no permite por sí misma hacer frente al efecto debilitador —en muchos casos deliberadamente perseguido- que las estrategias de segmentación pueden tener sobre la efectividad de los derechos mencionados, sobre todo cuando el sindicato opera en el ámbito empresarial y la negociación colectiva se desenvuelve a ese nivel. Un efecto que puede ser conseguido sin necesidad de vulnerar precepto legal alguno, mediante el empleo sin más, en principio lícito, de esta técnica.

Algo parecido puede decirse de lo indicado por los apartados 1 y 2 del citado precepto. Mientras el primero garantiza a los trabajadores implicados en estos procesos, que laboren con contratos de duración determinada, «iguales derechos que los trabajadores contratados a tiempo indeterminado», el segundo declara que los «que realicen labores en las instalaciones de la empresa principal en una tercerización» disponen de «todos los derechos laborales individuales y colectivos establecidos por la normativa vigente». Estas son previsiones que serían de extrema trascendencia si tuviesen como punto de referencia a la empresa principal, en cuyo ciclo productivo se integra en última instancia la actividad de estos trabajadores. No es este el caso, ya que la norma se cuida de aclarar que los derechos en cuestión los ostentan dichos trabajadores «respecto de su empleador», vale decir, la empresa contratista. La externalización puede ser utilizada válidamente aquí también pues como un instrumento para eludir las condiciones que la principal debe aplicar a su personal, asegurándose prestaciones equivalentes de trabajadores «externos» con beneficios laborales inferiores. 
Así las cosas, la cuestión de los efectos desfavorables del recurso no necesariamente fraudulento o ilícito a la «tercerización», que fue la que determinó la emergencia de la tendencia a regular estos fenómenos, se encuentra todavía, pese a los avances realizados, pendiente de ser afrontada por prácticamente todos los ordenamientos de la región.

\section{ALGUNAS ALTERNATIVAS VIABLES PARA EMPEZAR A AFRONTAR EL PROBLEMA DESDE LA AUTONOMÍA COLECTIVA}

Crear instrumentos que impidan, limiten o creen alguna garantía frente a los potenciales efectos degradatorios de las condiciones laborales que la utilización de estas técnicas es capaz de facilitar constituye una tarea extraordinariamente difícil, para la que no existen demasiadas referencias a nivel comparado. Sin embargo, resulta ineludible llevarla a cabo si queremos garantizar que las normas e instituciones laborales puedan seguir cumpliendo en el futuro la función equilibradora y, a la vez, fomentadora de la redistribución de los frutos del esfuerzo económico de nuestras sociedades, que justifica su existencia.

Con seguridad, la cuestión más delicada de todas las que es preciso abordar, pero a la vez de más necesaria atención, es la relativa a la brecha entre los salarios y las demás condiciones de trabajo de los trabajadores internos, vinculados directamente a la empresa principal, y los trabajadores de contrata, dependientes exclusivamente del contratista. La subcontratación está en condiciones de dar lugar a esta brecha de manera generalizada.

Este es, como salta a la vista, un efecto de los procesos de externalización que resulta más difícil de combatir desde la ley. Aun así, tampoco parece que los ordenamientos laborales tengan que resignarse a admitir que la segmentación de tareas que en última instancia forman parte de un único ciclo de producción permite eludir sin dificultad alguna el orden normativo aplicable al personal de la empresa principal. Antes bien, la constatación de la existencia de dicha unidad sustancial debería ser capaz de permitir avanzar en la construcción de instrumentos que permitan cerrar $\longrightarrow \mathrm{O}$ al menos acortar — la brecha que normalmente separa a ambos colectivos.

El instrumento más idóneo para ello estaría constituido por el establecimiento de una obligación de igualdad de trato entre los trabajadores dependientes de la empresa contratista y aquellos que laboran para la empresa que se beneficia indirectamente de su trabajo. La imposición de esta obligación se ve dificultada, no obstante, por importantes obstáculos formales. En especial, por la diferencia que puede existir entre las funciones que realizan los empleados de la contratista 
y las que corresponden a los de la principal, especialmente cuando las actividades externalizadas pertenecen a sectores mercantiles distintos y se rigen por convenios diferentes. A pesar de ello, la introducción del canon paritario resultaría perfectamente posible —y además legítimaal menos cuando unos y otros lleven a cabo funciones semejantes. Y más aun si, como empieza a ocurrir con frecuencia, los trabajadores de contrata desarrollan esas tareas en contacto estrecho con los de la empresa principal o en los centros de trabajo de esta.

La oposición que una propuesta de este tipo está en condiciones de generar, en especial por parte de quienes se encuentran habituados a utilizar este mecanismo en clave puramente abaratadora de costos laborales, unida a los límites formales que tendría su aplicación, aconsejan tener en cuenta otras opciones que contribuyan a generar un resultado semejante o, al menos, a aproximarse a él.

La vía principal para avanzar en esta dirección está constituida por la instrumentalización de los derechos de organización y acción colectiva de los trabajadores. Naturalmente, el ejercicio de estos derechos debería experimentar una importante transformación, dirigida a adaptarlo a la nueva situación. En opinión de quien escribe, esta transformación podría seguir, al menos, los derroteros que se detallan a continuación.

Así, antes que nada, los sindicatos deberán alterar sus modelos tradicionales de organización con el fin de adoptar otros más próximos a la nueva configuración de los proyectos empresariales y las formas de ejercicio del poder dentro de ellos. La clave estaría en crear instancias de representación que sean capaces de reflejar la complejidad actual de las formas de organización empresarial e implicar a quienes, de forma real, ejercen el poder dentro de ellas. Es decir, por lo general, la empresa principal o matriz, que se sitúa en el vértice de las cadenas de subcontratación.

Las modalidades de organización que se elijan pueden ser diversas, dependiendo de los sectores y las actividades de los que se trate, aunque es esencial que superen el estrecho marco de las empresas contratistas aisladamente consideradas. Puede tratarse de sindicatos de rama de actividad (si la actividad de la empresa principal y la de los contratistas coinciden), de sindicatos de territorio (si esa coincidencia de actividades no se produce pero la red ocupa un espacio geográfico determinado) o incluso de empresas contratistas pertenecientes a un mismo sector productivo, territorio o que desarrollan sus actividades para una misma empresa matriz. Es decir, sindicatos de red. Lo esencial aquí es que se generen fórmulas de agregación de intereses que reflejen las agregaciones que se vienen produciendo desde la perspectiva económica. 
Por lo que respecta a la negociación colectiva, el modelo de empresa red que subyace al empleo de estas técnicas debería propiciar una valoración de las condiciones de trabajo en términos de ciclo productivo, que permita identificar todas las actividades que intervienen en la producción de los bienes o servicios de los que se trate, con el fin de impulsar procesos de negociación colectiva que, abarcándolas, procuren asegurar beneficios laborales aceptables para el conjunto de los trabajadores que en ellos intervienen.

Las vías a través de las cuales podría avanzarse hacia este objetivo son varias, por lo demás no incompatibles entre sí. De entre ellas, tienen especial relieve en mi opinión las siguientes:

- Desarrollo de la negociación colectiva de sector basada, además, en unidades de amplia dimensión desde el punto de vista funcional que sean capaces de cubrir a través de un solo convenio las actividades de las empresas principales y sus subcontratistas, evitando así que la subcontratación pueda tener un efecto huida del convenio aplicable. Aquí el mejor ejemplo está constituido por la negociación colectiva del sector de la construcción, que en todos los ordenamientos donde se encuentra prevista garantiza un tronco de beneficios similares a todos los trabajadores que laboran en las cadenas de subcontratación de este sector, sin importar el eslabón en el que se sitúen.

- Creación de ámbitos transversales de negociación y formas de contratación colectiva reticular, ya sean estas territoriales, interempresas o de red, en las que el protagonismo venga asumido por la negociación entre las empresas principales y contratistas, en vez de solo, y principalmente, entre estas últimas y su personal.

- Introducción en los convenios colectivos de las empresas principales, seguramente a demanda o por presión de los trabajadores de núcleo afectados por la competencia del menor costo de la contratación indirecta, de cláusulas que traten de asegurar a los trabajadores de contrata un conjunto de condiciones laborales dignas a modo de cláusula social cuyo cumplimiento estas empresas obligan a exigir a sus contratistas como condición para la creación o el mantenimiento de una relación comercial duradera con ellos. Esto es algo que, de hecho, viene ocurriendo ya en el ámbito de las empresas multinacionales, donde muchas tienen previstos códigos de conducta en materia laboral o han suscrito acuerdos marco internacionales que regulan condiciones laborales a ser respetadas por sus contratistas si aspiran a mantener su condición de tales. 
Naturalmente, tampoco este es un itinerario fácil de seguir. Los obstáculos para que puedan extenderse estas nuevas formas de organización y negociación, sin embargo, no son tanto jurídicos como sociológicos. Estos inconvenientes radican, como es evidente, en la dificultad de que los trabajadores se doten efectivamente de representaciones adecuadas a la nueva situación, superando la atomización propiciada por el nuevo modelo de organización empresarial. Una dificultad de partida a la que hay sumar las potenciales resistencias del sector empresarial a comprometerse jurídicamente con modelos nuevos de contratación como los aludidos.

Con todo, ya en la etapa previa a la aprobación de las normas que han sido reseñadas a lo largo del artículo que aquí concluye se desarrollaron en algunos países de la región interesantes iniciativas por parte de los trabajadores de contrata de algunos sectores dirigidas a reducir la distancia de sus condiciones laborales respecto de las que aplicaba la principal, basadas en la conformación de sindicatos de base horizontal, aglutinadores de todos los trabajadores que laboran para los contratistas de una misma empresa, y la negociación conjunta de ciertas condiciones de trabajo con participación de la matriz. Allanar los obstáculos formales que se oponen a estas iniciativas en algunos sistemas, en particular en cuanto al registro de un sindicato de tales características, ofreciendo además respaldo normativo a los instrumentos atípicos a los que esta peculiar negociación a tres bandas puede ser capaz de dar lugar, podría ser una buena manera de empezar a recorrer, a partir del fortalecimiento de la autonomía colectiva tan venida a menos en los últimos años en la región debido al impacto de las políticas flexibilizadoras, este camino sin el cual que los esfuerzos desplegados hasta el momento a nivel legislativo no estarán en condiciones de cumplir de forma plena los objetivos que inspiraron su puesta en marcha.

LA REGULACIÓN DE LOS EFECTOS LABORALES DE LA SUBCONTRATACIÓN: EL PERÚ EN AMÉRICA DEL SUR

THE REGULATION OF THE LABOR EFFECTS OF SUBCONTRACTING: PERU IN SOUTH AMERICA 